\title{
The role of letter identity and letter position in orthographic priming
}

\author{
FRANCESCA PERESSOTTI \\ University of Padua, Padua, Italy \\ and \\ JONATHAN GRAINGER \\ CNRS and University of Provence, Aix-en-Provence, France
}

\begin{abstract}
Four experiments are reported investigating orthographic priming effects in French by varying the number and the position of letters shared by prime and target stimuli. Using both standard masked priming and the novel incremental priming technique (Jacobs, Grainger, \& Ferrand, 1995), it is shown that net priming effects are affected not only by the number of letters shared by prime and target stimuli but also by the number of letters in the prime not present in the target. Several null results are thus explained as a tradeoff between the facilitation generated by common letters and the inhibition generated by different letters. Inhibition was significantly reduced when different letters were replaced by nonalphabetic symbols. Facilitation effects disappeared when the common letters did not have the same relative position in the prime and target strings, thus supporting a relative-position coding scheme for letters in words.
\end{abstract}

The idea that letters are basic perceptual units in the process of visual word recognition is nowadays widely accepted (e.g., Besner \& McCann, 1987; Grainger \& Jacobs, 1996; McClelland \& Rumelhart, 1981; Paap, Newsome, McDonald, \& Schvaneveldt, 1982). More precisely, many authors claim that the relevant information used in recognizing visually presented words is abstract letter identity that is independent of type font and case (Egeth \& Santee, 1981; Evett \& Humphreys, 1981; Peressotti, Job, Rumiati, \& Nicoletti, 1995). In mapping letter identities onto whole-word representations in memory, it is clear that information about letter position must also be computed. The importance of this type of information is evident if we consider that alphabetic languages, such as English and French, have large numbers of anagrams. We are able to distinguish words containing the same letters (e.g., bale-able) on the basis of the different position of the letters in the string. How do skilled readers code such position information?

One hypothesis is that letter identity and letter position are computed at the same time, so that the coding unit would not be the letter per se but the letter in a given position (McClelland \& Rumelhart, 1981; Paap et al., 1982).

This research was supported by a postdoctoral fellowship awarded to the first author from the Fyssen Foundation, Paris, and by a grant from CNR, Italy. The authors thank Thomas Sanocki, Jay Rueckl, and one anonymous reviewer for constructive criticism of an earlier version of this work. Special thanks to Lester Krueger for his expert handling of this and other work that we have published in this journal. Correspondence should be addressed to F. Peressotti, DPSS, Università di Padova, Via Venezia, 8, 35132 Padua, Italy (e-mail: peressot@psico.unipd.it).

-Accepted by previous editor, Myron L. Braunstein
This is an example of conjunctive coding in which the identity and role of a given object are coded by the same processing unit. For example, according to the interactive activation (IA) model of McClelland and Rumelhart (1981), letters within words are processed in parallel by a set of position-specific letter detectors. Each letter is processed by an independent channel that extracts and analyzes letter features in a specific position. The output of feature detectors sends activation to a set of letter detectors for that channel. According to this model, position information is automatically coded, and a given letter is always recognized in a certain position within the string. A letter recognized in one position would activate all words containing that letter in that position. So, in this model, anagrams would not prime each other. The activation of the letter nodes $a, b, l$, and $e$ would activate the word able and all four-letter words that contain the letter $a$ in the first position, the letter $b$ in the second, and so on. However, the $a$ and $b$ in able will not activate word nodes that have the same letters in a different position (as in bale).

The assumption of independent processing channels for each letter position makes the model quite rigid. In previous work (Peressotti \& Grainger, 1995), we found evidence in favor of position-independent letter coding that the rigid version of the IA model could not account for. Using random consonant trigrams as stimuli, we found both position-specific and position-independent priming effects. A letter in a given position within a string successfully primed a string containing the same letter in the same position, but it also successfully primed a string containing the same letter in an adjacent position. Furthermore, the priming effect varied as a function of the degree of displacement. The farther apart the positions of the letter in 
the prime and in the target, the smaller the priming effect obtained. This result suggests that position coding is not $100 \%$ accurate and that evidence that a given letter is present in a given position in a string is also taken as evidence that the same letter is present in a neighboring position.

In the present study, we examined whether the positionindependent priming effects observed with consonant trigrams will extend to paradigms using real words as stimuli. Indeed, it might be argued that the material and the task used in our previous study could have induced stringinto-letter segmentation, since letters were the only significant units. The aim of the present study was to investigate letter position effects when the task is lexical decision and the stimuli are words. Using words as targets allows us to address the important issue of how position information about constituent letters is represented in long-term memory. In line with the position-independent priming effects obtained with consonant trigrams, there is some evidence to suggest that constituent letters are not coded for their absolute position in the word. On the contrary, the available evidence favors a coding scheme in which a given letter's position is represented relative to some critical reference points (e.g., the beginning and end of the word). We refer to this as relative-position coding. We turn now to evaluate the relevant evidence.

Humphreys, Evett, and Quinlan (1990) were the first to systematically investigate the effects of number and position of shared letters in an orthographic priming paradigm with word stimuli. They used a four-field masking procedure in which primes (nonwords) and targets (words) were briefly presented one after the other. Immediately before the prime and after the target, two masking patterns were displayed. The subjects' task was to recognize the target word presented in uppercase letters. The exposure durations of the four fields were adjusted so that subjects correctly reported about $40 \%$ of targets. The results showed that priming effects varied as a function of both the number and the position of letters shared by primes and targets of the same length. Greater degrees of orthographic overlap produced larger priming effects, but only when shared letters occupied the same position in primes and targets. In the same study, however, priming effects were also obtained when primes and targets differed in length. So, for example, the sequence $b v k$ facilitated the identification of the word BLACK with respect to the neutral condition ovf just as well as the sequence btvuk with respect to the neutral condition otvuf. External letters primed only external letters, internal letters primed only internal letters, and priming effects were stronger when prime and target stimuli had the same external letters than when they had the same internal letters.

The work of Humphreys et al. (1990) suggests that letters are coded for their relative position in a given string rather than their absolute (length-dependent) position. There are, however, a number of problems with this study that have motivated the extension provided in the present work. First of all, it has been shown that the procedure used by the authors, the four-field masking technique, has a crucial inherent problem. According to Davis and Forster (1994), orthographic priming effects obtained with this paradigm might be explainable on the basis of variations in the legibility of the target when superimposed on the prime image. When primes and targets share letters, even when written in different case, they share more subletter featural information than when there is no orthographic overlap. When the two stimuli are superimposed this leads to greater target legibility. Davis and Forster showed that target recognition increased when primes shared such low-level feature information with targets, without sharing letters. They also demonstrated that this preorthographic priming effect depends on target duration. When the target stimulus remained visible for a long time and the task was lexical decision, the effects disappeared. So, the first question we would like to address is, Could Humphreys et al.'s results be replicated when the target is exposed for a long time and the task is lexical decision?

\section{PILOT STUDY}

Some initial pilot work suggested a negative response to the above question. In several experiments using a variant of the masked priming procedure first described by Forster and Davis (1984), we had great difficulty in finding any significant priming when primes shared only two letters of four-letter target words. In order to control for effects of low-level featural overlap, in one preliminary study to be reported in some detail here, we systematically varied the size and the case of prime stimuli (target size and case remained constant). Thus, prime stimuli were presented in either lowercase or uppercase and either the same size as or smaller than the target stimuli, which were presented in uppercase. Primes either shared the first letter and the last letter of targets (e.g., JKZR-JOUR) or contained only unrelated letters (e.g., DKZM-JOUR). The design is summarized in Table 1. Eighty four-letter French words and 80 pronounceable, orthographically regular nonwords were tested in the eight priming conditions resulting from the factorial combination of these three factors. Forty-eight students at the University of Provence participated as subjects. The size of prime stimuli was manipulated between subjects, with 24 subjects in each condition. The other two factors were manipulated within subjects. Prime-target pairing was counterbalanced across four different lists, such that each subject was tested in the four priming conditions arising from the combination of the two within-subjects factors, but each subject saw each target stimulus once only. The procedure used was a variant of the masked prime procedure accompanied with the lexical decision task. On each trial, subjects saw four hash marks (\#\#\#), which served as a fixation mark and remained in view for $400 \mathrm{msec}$. Then, the prime stimulus was displayed for $33 \mathrm{msec}$ and was immediately followed by the target, which remained on the screen until subjects' response or for a maximum time of $1,000 \mathrm{msec}$.

Analyses of variance (ANOVAs) performed on the correct response times (RTs) to word and nonword stimuli, 
Table 1

Examples of the Prime Stimuli Used in the Pilot Study and Experiments 1-4

\begin{tabular}{|c|c|}
\hline Prime Type & Prime \\
\hline \multicolumn{2}{|c|}{ Pilot Study } \\
\hline \multicolumn{2}{|l|}{ Same } \\
\hline \multicolumn{2}{|l|}{ Lowercase } \\
\hline Small & jkzr \\
\hline Big & jkzr \\
\hline \multicolumn{2}{|l|}{ Uppercase } \\
\hline Small & JKZR \\
\hline Big & JKZR \\
\hline \multicolumn{2}{|l|}{ Different } \\
\hline \multicolumn{2}{|l|}{ Lowercase } \\
\hline Small & $\mathrm{dkzm}$ \\
\hline $\mathrm{Big}$ & $\mathrm{dkzm}$ \\
\hline \multicolumn{2}{|l|}{ Uppercase } \\
\hline Small & DKZM \\
\hline $\mathrm{Big}$ & DKZM \\
\hline \multicolumn{2}{|c|}{ Experiment 1} \\
\hline SDDS & JKZR \\
\hline $\mathbf{S}++\mathbf{S}$ & $J_{++} R$ \\
\hline \multirow[t]{2}{*}{ DDDD } & DKZM \\
\hline & \\
\hline \multicolumn{2}{|l|}{ Same } \\
\hline Four letters & BLCN \\
\hline Six letters & BSLCRN \\
\hline \multicolumn{2}{|l|}{ Different } \\
\hline Four letters & TPVF \\
\hline Six letters & TSPVRF \\
\hline \multicolumn{2}{|c|}{ Experiment 3} \\
\hline 1346 & BLCN \\
\hline 1436 & BCLN \\
\hline 6341 & NLCB \\
\hline DDDD & TPVF \\
\hline \multicolumn{2}{|c|}{ Experiment 4} \\
\hline 1346 & BLCN \\
\hline $1-34-6$ & $B-L C-N$ \\
\hline $1 \% 34 \% 6$ & $\mathrm{~B} \% \mathrm{LC} \% \mathrm{~N}$ \\
\hline$\% \% \% \% \% \%$ & $\% \% \% \% \% \%$ \\
\hline
\end{tabular}

Note-For the pilot study and Experiment 1, the target was JOUR. For Experiments 2-4, the target was BALCON.

as well as on the arcsine transformations of percent errors, showed no significant main effects nor any interaction effects. Thus, independently of the case and the size of the prime stimulus, no effect on target recognition was obtained. A prime sharing the two external letters with the target did not help target recognition relative to a prime sharing no letters. This null effect occurred even when the common letters of the prime and the target were physically overlapping (when primes were the same size and in the same case as targets).

The experiments to be reported below examine two possible reasons for the difficulty in obtaining significant orthographic priming effects when primes share two out of four letters of target words. These concern (1) the role of unrelated letters in the prime stimulus and (2) the degree of prime-target orthographic overlap. We hypothesize that unrelated letters in the prime stimulus generate interference during target processing. It is therefore possible that each common letter facilitates target recognition to a certain amount and that, at the same time, each unrelated letter produces a certain amount of interference. Only when the facilitation is stronger than the interference can an advantage in target recognition be obtained. In Experiment 1, the unrelated letters of prime stimuli were replaced by a plus $(+)$ sign. Experiment 4 tested for an influence of the visual complexity of filler characters using percentage (\%) and minus ( - ) signs. Furthermore, the number of letters shared by primes and targets was increased from two out of four letters in Experiment 1 (see also Pilot Study) to four out of six letters in Experiments 2,3 , and 4 .

In the present experiments, we addressed these two critical issues while also testing for effects of letter position in orthographic priming. In Experiments 2 and 4, we compared effects of prime letters having the same absolute position as in the target stimulus (e.g., BSLCRN-BALCON) with the effects of prime letters having the same relative position (e.g., BLCN-BALCON). In Experiment 3, we compared the effects of relative-position primes with the effects of primes in which relative position was violated (e.g., BCLN-BALCON). In Experiments 1, 3B, and 4, we used the incremental priming technique (Jacobs, Grainger, $\&$ Ferrand, 1995) in order to provide critical information on the time course of priming effects and also to provide an additional baseline (the within-condition baseline, to be explained below) for measuring inhibitory and facilitatory influences on target processing.

\section{EXPERIMENT 1}

Jacobs et al. (1995) used a prime intensity increment method to measure the size of the priming effects for each priming condition with respect to a "minimum intensity" baseline. In the present work, we manipulated prime duration rather than prime intensity. In the within-condition baseline, the prime was exposed for $0 \mathrm{msec}$. Obviously, in this condition, no influence on target processing was expected. Then, prime exposure was gradually increased (17, 33 , and $50 \mathrm{msec}$ ). If RTs decrease with respect to this within-condition baseline, we can conclude that the prime facilitates target processing. Alternatively, if RTs increase as a function of prime duration, we can conclude that the prime inhibits target processing.

\section{Method}

Subjects. Eight graduate students at the University of Provence volunteered to participate as subjects. All were French native speakers and had normal or corrected-to-normal vision.

Stimuli and Design. A subset of 60 words and 60 nonwords of the pilot study were used as target stimuli. Three priming conditions were devised. In one condition, primes had the same external letters as the targets, and the two middle letters were replaced by two different consonants (SDDS condition). In a second condition, the external letters were always the same, but the middle letters were replaced by two plus signs ( $\mathrm{S}++\mathrm{S}$ condition). Finally, in the third condition, the primes were formed by four unrelated consonants (DDDD condition). These three conditions gave the three lev- 


\section{EXPERIMENT 1: WORDS}

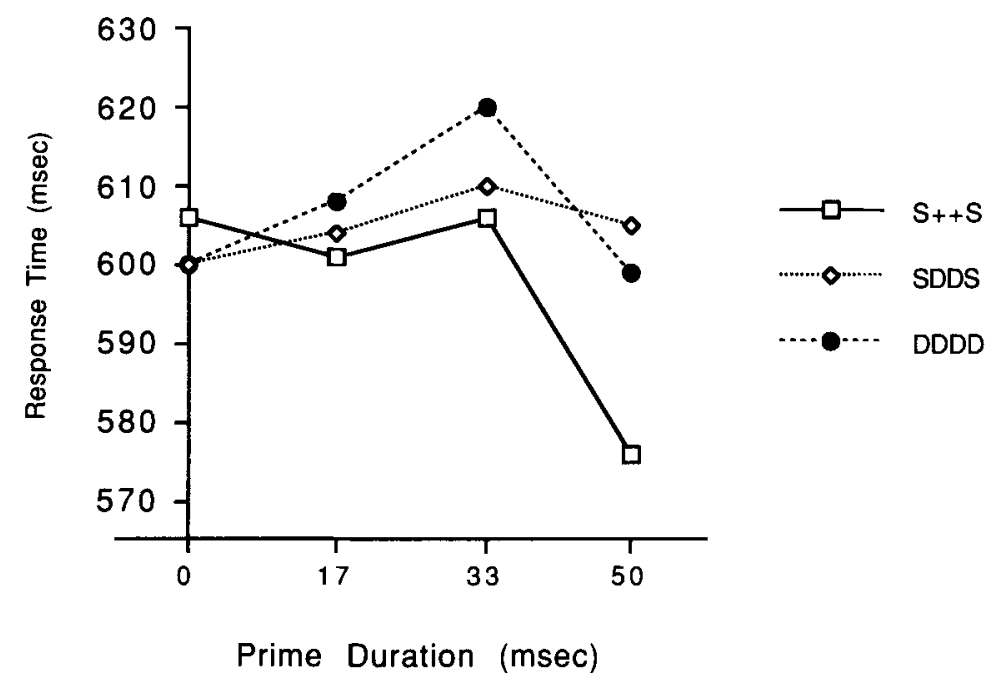

Figure 1. Variation in mean RT (in milliseconds) as a function of prime exposure duration and prime type in Experiment 1. S denotes same letter as in target; $D$ denotes a different letter from the target; "+" indicates that this sign figured in the prime stimulus.

els of the factor prime type (see Table 1). Primes were exposed for $0,17,33$, or $50 \mathrm{msec}$, giving the four levels of the factor prime duration. Three experimental lists were constructed in which primetarget pairs were rotated according to a Latin-square design, so that a given target was primed by one type of prime in one list and by a different type of prime in another list. Each list contained $120 \mathrm{stim}$ uli ( 60 words and 60 nonwords), 40 preceded by an SDDS prime, 40 by an $S++S$ prime, and 40 by a DDDD prime. Each subject received the three lists in a random order on four different days, with a different prime duration on each day, giving a total of 60 observations per experimental condition per subject. The order of prime duration was counterbalanced according to a Latin square, with 2 subjects assigned to each of the four possible orders.

Procedure. Each trial consisted of three stimuli presented one after the other. The first was a row of four hash marks (\#\#), which served as fixation and remained in view for $400 \mathrm{msec}$. The second was the prime stimulus that was displayed for $0,17,33$, or $50 \mathrm{msec}$ and was immediately followed by the third stimulus, the target, which lasted until the subjects' response or for a maximum time of $1,000 \mathrm{msec}$. All three stimuli appeared in the center of a Macintosh Classic computer screen. Both prime and target stimuli were in uppercase, but, in order to minimize physical overlap, they had different sizes. Each letter of the prime was $0.2 \mathrm{~cm}$ high and $0.15 \mathrm{~cm}$ wide; each letter of the target was $0.3 \mathrm{~cm}$ high and $0.2 \mathrm{~cm}$ wide. Primes were displayed using a font in which each character occupied the same space, so that all prime types had the same length $(0.9 \mathrm{~cm})$. Targets measured $1.3 \mathrm{~cm}$ in length. The subjects sat in front of the computer at a viewing distance of approximately $60 \mathrm{~cm}$. At that distance, the prime and the target stimuli subtended $1.71^{\circ}$ and $2.48^{\circ}$ of visual angle, respectively.

The subjects were instructed to decide as rapidly and as accurately as possible whether or not the target was a French word. The presence of a prime was not mentioned. They responded "yes" by pressing one response button with the forefinger of the preferred hand and "no" by pressing the other response button with the forefinger of the other hand. The response buttons selected were the command key and the zero (0) key of the Macintosh Classic keyboard (respectively, the bottom leftmost key and the bottom rightmost key of the keyboard). After the subjects' response, there was a delay of $800 \mathrm{msec}$ before the next trial started. Stimulus presentation was randomized within each block with a different order for each subject. RTs were measured to the nearest $17 \mathrm{msec}$.

\section{Results and Discussion}

Mean RT for each prime type and prime exposure duration are given in Figure 1.

ANOVAs by subjects $(F 1)$ and by items $(F 2)$ were performed on the mean correct RTs to words, with prime type and prime duration as within-subjects and within-items factors. There was a significant main effect of prime type $\left[F 1(2,14)=9.39, M S_{\mathrm{e}}=88.89, p<.01 ; F 2(2,188)=7.61\right.$, $\left.M S_{\mathrm{e}}=1,188.12, p<.001\right]$ and a significant prime type $\times$ prime duration interaction $\left[F 1(6,42)=5.00, M S_{\mathrm{e}}=111.11\right.$, $\left.p<.001 ; F 2(6,354)=2.59, M S_{\mathrm{e}}=1,090.54, p=.02\right]$. When the prime was presented for 0 or $17 \mathrm{msec}$, no significant differences emerged across priming conditions or between the two prime durations. At $33 \mathrm{msec}$, a significant effect of prime type was observed. Planned comparisons among the means showed that the DDDD condition produced longer RTs than did either the $\mathrm{S}++\mathrm{S}$ condition or the SDDS condition $\left[F 1(1,42)=7.81, M S_{\mathrm{e}}=\right.$ $111.11, p<.01$, and $F 1(1,42)=3.94, M S_{\mathrm{e}}=111.11, p=$ .053 , respectively]. As can be seen in Figure 1, this effect follows from the within-condition inhibitory effect of the DDDD condition at $33 \mathrm{msec}\left[F 1(1,42)=14.40, M S_{\mathrm{e}}=\right.$ $111.11, p<.001]$. At $50 \mathrm{msec}$, on the other hand, a withincondition facilitation was observed for the $\mathrm{S}++\mathrm{S}$ condition $\left[F 1(1,42)=31.84, M S_{\mathrm{e}}=111.11, p<.001\right]$. In this condi- 
Table 2

Mean RTs (in Milliseconds) and Percent Errors (PEs) Obtained to Nonword Targets in Experiment 1 as a Function of Prime Type and Prime Duration

\begin{tabular}{|c|c|c|c|c|c|c|c|c|}
\hline \multirow[b]{3}{*}{ Prime Type } & \multicolumn{8}{|c|}{ Prime Duration (msec) } \\
\hline & \multicolumn{2}{|c|}{0} & \multicolumn{2}{|c|}{17} & \multicolumn{2}{|c|}{33} & \multicolumn{2}{|c|}{50} \\
\hline & RT & $\mathrm{PE}$ & RT & $\mathrm{PE}$ & RT & $\mathrm{PE}$ & RT & $\mathrm{PE}$ \\
\hline $\mathrm{S}++\mathrm{S}$ & 615 & 5.3 & 626 & 5.8 & 611 & 5.0 & 612 & 5.9 \\
\hline SDDS & 621 & 5.6 & 622 & 6.4 & 618 & 6.1 & 611 & 5.0 \\
\hline DDDD & 615 & 5.6 & 626 & 6.5 & 616 & 5.2 & 613 & 4.4 \\
\hline
\end{tabular}

tion, RTs were shorter than those in both the SDDS condition and the DDDD condition $\left[F 1(1,42)=30.55, M S_{\mathrm{e}}=\right.$ $111.11, p<.0001$, and $F 1(1,42)=18.36, M S_{\mathrm{e}}=111.11$, $p=.0001$, respectively].

Since few errors were made to word stimuli and since a large number of cells contained the values 0 or 0.12 , error rates were arcsine-transformed such that an ANOVA could be performed, as with the RT data. The analysis showed no significant effects or interactions [all $F \mathrm{~s}<1$, except for prime duration, $F(3,21)=2.06, M S_{\mathrm{e}}=0.007$, $p=.14]$. The average error rates for the S++S, SDDS, and DDDD prime types, respectively, at each prime exposure were as follows: $0 \mathrm{msec}=9.1,10.2$, and $9.7 ; 17 \mathrm{msec}=$ $10.2,10.2$, and $9.5 ; 33 \mathrm{msec}=9.4,10.1$, and 11.4; $50 \mathrm{msec}=10.8,10.5$, and 11.2 .

Nonword data are reported in Table 2. The ANOVA by subjects conducted on the correct RTs to nonwords with the same factors as used in the analysis on RTs to words did not show any significant main effect or interaction (all $F$ s $<1$ ).

Orthographic priming effects thus seem to depend on both the interference generated by the unrelated letters at $33 \mathrm{msec}$ and the facilitation generated by the common letters $(\mathrm{S}++\mathrm{S})$ at $50 \mathrm{msec}$. Target processing was indeed slowed down by the unrelated letter primes and speeded up by common letter primes. However, when the prime contained two common letters and two unrelated letters, neither facilitatory nor inhibitory effects were found (as in the pilot study). This suggests that a tradeoff between the facilitation due to the two common letters and the inhibition due to the two unrelated letters was arising in this specific condition. On the one hand, the presence of two common letters mitigated the inhibitory effect with respect to the DDDD condition; on the other hand, the presence of two unrelated letters mitigated the facilitatory effect with respect to the $\mathrm{S}++\mathrm{S}$ condition. The withincondition inhibition that emerged before (at $33-\mathrm{msec}$ prime exposures) within-condition facilitation (at 50-msec prime exposures) in the present experiment might have been due to the fact that the inhibition resulted from four different letters, whereas the facilitation was produced only by two common letters.

\section{EXPERIMENT 2}

The pattern of results obtained in the SDDS condition of Experiment 1 suggests that the lack of positionspecific letter priming in the pilot study can be explained by the interference generated by letters in the prime stimulus that are not present in the target. According to this hypothesis, while the common letters facilitated target recognition, the unrelated letters produced inhibition, thus masking any facilitatory priming. The aim of Experiment 2 was to test the hypothesis of position specificity in letter coding in conditions in which the number of common letters is greater than the number of unrelated letters. It should be noted that this is generally the case in masked priming studies using the lexical decision task in which significant facilitation effects of prime-target orthographic overlap have been observed (e.g., Ferrand \& Grainger, 1992, 1994; Forster, Davis, Shocknecht, \& Carter, 1987). It should also be noted, however, that these orthographic priming studies not only had greater prime-target overlap than in the pilot study but also fewer unrelated letters in the prime (systematically only one mismatching letter). In Experiment 2, we tested orthographic priming effects using primes that shared four out of six letters with targets and had either zero or two unrelated letters.

Six-letter French words were used as targets. Primes shared four letters with targets. Furthermore, prime length was varied, so that primes were six letters long in one condition and four letters long in another condition. In the first condition, the prime contained four common letters, placed in the same specific position as in the target, and two unrelated letters. In the second condition, only four common letters were included in the prime, and they had the same relative position as in the target.

\section{Method}

Subjects. Twenty-eight undergraduate students at the University of Provence volunteered to participate as subjects. All were French speakers and had normal or corrected-to-normal vision.

Stimuli and Design. Sixty French words six letters long (with a mean frequency of 105 occurrences per million; Imbs, 1971) formed by four consonants and two vowels were selected as target words. All of them began and ended with a consonant. Sixty nonwords six letters in length with the same orthographic structure (i.e., arrangement of consonants and vowels) as word targets were created by changing one letter from existing words. All resulted in a pronounceable sequence not homophonic to any real word. The primes were consonant strings. In one condition, primes contained the four consonants of corresponding targets (same primes), and, in another condition, primes and targets had no letters in common (different primes), giving the two levels of the factor prime type. Prime length was also varied: Prime strings could be either six letters long or four letters long. In the same condition, the six-letter primes contained the four consonants of the target word plus two added consonants placed in the same position as the vowels of the target (e.g., bslcrn for the target word BALCON); the four-letter primes were formed 
Table 3

Mean RTs (in Milliseconds) and Percent Errors (PEs) Obtained in Experiment 2 as a Function of Prime Length and Prime Type

\begin{tabular}{|c|c|c|c|c|c|}
\hline \multirow[b]{3}{*}{ Prime Length } & \multicolumn{4}{|c|}{ Prime Type } & \multirow[b]{3}{*}{ Difference } \\
\hline & \multicolumn{2}{|c|}{ Same } & \multicolumn{2}{|c|}{ Different } & \\
\hline & RT & $P E$ & RT & PE & \\
\hline \multicolumn{6}{|c|}{ Words } \\
\hline Four letters & 623 & 4.05 & 650 & 2.85 & -27 \\
\hline Six letters & 629 & 4.76 & 641 & 3.57 & -12 \\
\hline \multicolumn{6}{|c|}{ Nonwords } \\
\hline Four letters & 727 & 3.75 & 728 & 5.71 & -1 \\
\hline Six letters & 728 & 3.81 & 730 & 4.52 & -2 \\
\hline
\end{tabular}

Note-In all conditions, targets were six-letter words or nonwords.

by the four consonants of the target in the same relative position (e.g., blcn). In the different condition, the six-letter primes consisted of six unrelated letters (tspvrf) and the four-letter primes of four unrelated letters $(t p v f)$. Thus, prime type and prime length were crossed in a $2 \times 2$ factorial design, and each target stimulus was presented in four different priming conditions (see Table 1). In order to avoid target repetition, four lists were constructed in which prime-target pairs were rotated according to a Latin-square design, so that one target stimulus was primed by a certain prime in one list and by a different prime in another list. Each list contained 120 stimuli ( 60 words and 60 nonwords), half preceded by a same prime and half by a different prime. There were 15 same and 15 different primes for each given prime length. The subjects were assigned to one of the four lists in the order they arrived for the experiment.

Procedure. The sequence of events on the screen is the same as in Experiment 1; however, the first stimulus of each trial was a row of six hash marks (instead of four). Prime and target size was different than in Experiment 1. Four-letter primes measured $1.4 \mathrm{~cm}$ in length, and six-letter primes measured $0.9 \mathrm{~cm}$ in length. At the viewing distance of $60 \mathrm{~cm}$, they subtended $1.71^{\circ}$ and $2.67^{\circ}$ of visual angle. Six-letter targets subtended $3.82^{\circ}$ of visual angle (as in Experiment 1 , prime size was smaller than target size). Prime duration was fixed at $33 \mathrm{msec}$. For the other details, the procedure was the same as that in Experiment 1.

\section{Results and Discussion}

Mean correct RTs and error percentages to word and nonword stimuli are reported in Table 3 . ANOVAs by subjects and by items were performed on correct RTs to word stimuli, with the two factors prime type and prime length as within-subjects and within-items factors. A significant effect of prime type was obtained $[F 1(1,27)=$ $18.36, M S_{\mathrm{e}}=543.30, p<.01 ; F 2(1,59)=6.72, M S_{\mathrm{e}}=$ $2,711.29, p=.01]$, but no main effect of prime length (both $F 1$ and $F 2<1$ ). Independently of prime length, RTs in the same prime condition were faster than in the different prime condition ( $626 \mathrm{msec}$ vs. $645 \mathrm{msec}$ ). The interaction between the two factors was not statistically significant $\left[F 1(1,27)=1.94, M S_{\mathrm{e}}=780.64, p=.18 ; F 2(1,59)=1.36\right.$, $\left.M S_{\mathrm{e}}=2,768.99, p=.29\right]$.

A priori planned comparisons among the means showed that when the prime was four letters long, RTs in the same prime condition were shorter than those in the different prime condition $\left[F 1(1,27)=12.34, M S_{\mathrm{e}}=780.64, p<\right.$ $\left..01 ; F 2(1,59)=6.59, M S_{\mathrm{e}}=2,768.99, p=.013\right]$. When the primes were six letters long, the difference between same and different primes was not significant $[F 1(1,27)=2.38$, $M S_{\mathrm{e}}=780.64, p=.134 ; F 2(1,59)=1.12, M S_{\mathrm{e}}=2,768.99$, $p=.29$ ]. Again, because of the low error rate and the low variability between cell values, we analyzed the arcsine transformations of percent errors. The ANOVA conducted with the factors prime type and prime length showed no significant main effects or interactions [all $F \mathrm{~s}<1$, except for prime length, $\left.F 1(1,27)=1.89, M S_{\mathrm{e}}=0.054, p=.18\right]$.

Correct RTs to nonword targets were submitted to an ANOVA by subjects with the two factors prime type and prime length. No source was significant (all $F \mathrm{~s}<1$ ).

Even when the letters of the prime were not placed in the same specific position as in the target, a significant facilitation on target word recognition was observed. However, when the letters of the prime were placed in the same specific position in the prime and in the target, but the prime string contained two additional unrelated letters, priming effects were no longer statistically significant. The latter result shows that the amount of orthographic overlap (in terms of proportion of common letters) is not the single critical factor responsible for priming effects to emerge. Even when the prime shared four out of six letters with the target word, no significant priming effects were obtained when primes contained two unrelated letters.

The pattern of results replicates the relative-position priming effects reported by Humphreys et al. (1990). However, unlike in the Humphreys et al. study, no significant priming effects were observed when the prime contained unrelated letters that provided the supplementary information for position-specific coding. Two main differences could be claimed to account for this contrasting result: target duration and prime size. In the present experiment, in which the task used was lexical decision, the target stimulus was exposed for long durations (until the subject's response), whereas, in Humphreys et al.'s study, the task was perceptual identification and the target stimulus was presented as briefly as the prime. Furthermore, in the present experiment, prime and target stimuli had different sizes, whereas Humphreys et al. varied prime versus target case, so that the two stimuli occupied the same portion of visual field. Both of these variables - prime size and target duration-play a crucial role in low-level fusion effects. As shown by Davis and Forster (1994) and Forster (1993), when the target is briefly exposed and occupies the same spatial region as the prime, fusion effects are obtained. Even when the prime and the target share no letters, a higher rate of target recognition is obtained if the superimposition of the prime and the target stimuli make the latter more legible. Thus, some of the priming effects reported in the Humphreys et al. study might have been caused by low-level fusion processes, and not higher level orthographic processes. In the present experiment, under conditions in which fusion effects were avoided (longer target exposure and smaller size of the prime), no priming was obtained when unrelated letters were present in the prime.

In line with the results of Humphreys et al. (1990), we did observe relative-position priming effects in Experiment 2. However, although this experiment tested for 
Table 4

Mean RTs (in Milliseconds) and Percent Errors (PEs) to Word and Nonword Stimuli Obtained in Experiment 3A as a Function of the Priming Conditions

\begin{tabular}{lccccccc}
\hline & \multicolumn{4}{c}{ Words } & & \multicolumn{3}{c}{ Nonwords } \\
\cline { 2 - 4 } \cline { 6 - 8 } Prime Condition & RT & PE & Difference & & RT & PE & Difference \\
\hline 1346 & 596 & 4.4 & -20 & & 708 & 5.5 & +11 \\
1436 & 611 & 5.2 & -5 & & 697 & 4.2 & 0 \\
6341 & 609 & 5.0 & -7 & & 701 & 7.2 & +4 \\
DDDD & 616 & 1.2 & & & 697 & 6.9 & \\
\hline
\end{tabular}

Note-The differences were calculated relative to the DDDD prime condition.

both absolute and relative-position priming, there was no control for position-independent priming effects. The aim of the next experiment was to test whether priming effects can be obtained when primes contain letters from the target word without respecting their relative position in the string. Our previous work with random consonant strings (Peressotti \& Grainger, 1995) suggests that positionin-string information should critically determine the size of priming effects.

\section{EXPERIMENT 3}

In Experiment 3, two new priming conditions were added to the relative-position priming conditions tested in Experiment 2. One condition involved switching the position of the two external letters of the target, and the other involved switching the two middle letters. So, for example, the word BALCON was primed by the sequence blcn in one condition (1346 condition), by the sequence $n l c b$ in another condition ( 6341 condition), by the sequence $b c l n$ in another condition ( 1436 condition), and by four unrelated letters $(f r d s)$ in the last condition (DDDD condition). Note that, in the first three conditions, primes were formed by the four consonants of the target, but only in the first condition was the correct relative order maintained. Furthermore, the inversion of either external or internal letters allowed us to test whether external letters play a predominant role in the word recognition process, as suggested by the results of Humphreys et al. (1990).

In Experiment 3A, a large group of subjects was tested under a single prime exposure duration $(33 \mathrm{msec})$; in Experiment $3 \mathrm{~B}$, a small group of subjects was tested using the incremental priming technique $(0-, 17-, 33-$, or $50-\mathrm{msec}$ prime exposures).

\section{Method of Experiment 3A}

Subjects. Twenty-four undergraduate students at the University of Provence volunteered to participate as subjects. All were French speakers and had normal or corrected-to-normal vision.

Stimuli and Design. The targets were six letters long $(2 \mathrm{~cm}$, $\left.3.82^{\circ}\right)$, as in Experiment 2, and primes were four letters long $\left(0.9 \mathrm{~cm}, 1.71^{\circ}\right)$. Four priming conditions were tested. In the first condition (1346 condition), the prime was formed by the four consonants of the target word in the same relative position as in the tar- get (this replicated the same condition of four-letter primes in Experiment 2 ). In the second condition ( 1436 condition), the prime was formed by the same consonants of the target, but the two middle letters were switched so that the second consonant was placed in the third position and, conversely, the third consonant in the second position, while keeping the two external letters in the correct relative position. In the third condition ( 6341 condition), the two external letters were switched so that the first was placed in the last position and, conversely, the last in the first position, but keeping the two middle letters in the correct relative position. Finally, the last condition (DDDD condition) was the same as the different condition of Experiment 2, and the prime string was formed by four unrelated letters. Each target stimulus was presented in the four priming conditions, giving the four levels of the factor prime type (see Table 1). As in Experiment 2, four lists were constructed in which prime-target pairs were rotated according to a Latin-square design. Each list contained 120 targets ( 60 words and 60 nonwords), 15 words and 15 nonwords for each prime condition.

Procedure. Stimulus presentation was controlled by a Macintosh Centris 650 computer, and RTs were recorded with $1-\mathrm{msec}$ accuracy using an external button box. The subjects were assigned to one of the four experimental lists as they arrived for the experiment. The stimulus presentation conditions were the same as in Experiment 2 , with only one prime duration set at $33 \mathrm{msec}$. The other details of the procedure were the same as in Experiment 2.

\section{Results and Discussion of Experiment $3 \mathrm{~A}$}

Mean correct RTs and error rates to the word and the nonword stimuli are reported in Table 4. As for Experiments 1 and 2, ANOVAs both by subjects and by items were performed on the correct mean RTs to word stimuli. The main effect of prime type was only marginally significant in the subjects analysis $\left[F 1(3,69)=2.58, M S_{\mathrm{e}}=\right.$ $663.15, p=.06]$, and it was not significant in the items analysis $\left[F 2(3,177)=1.24, M S_{\mathrm{e}}=2,388.15, p=.29\right]$.

A priori planned comparisons among the means showed that in the 1346 condition responses were faster than the DDDD condition responses $[F 1(1,69)=7.114$, $M S_{\mathrm{e}}=663.15, p<.01 ; F 2(1,177)=3.01, M S_{\mathrm{e}}=2,388.15$, $p=.08$ ], thus replicating the priming effect obtained in Experiment 2. The difference between the 1346 condition and both the 1436 condition and the 6341 condition was marginally significant in the subjects analysis and was not significant in the items analysis $\left[F 1(1,69)=3.93, M S_{\mathrm{e}}=\right.$ $663.15, p=.052, F 2(1,77)=2.48, M S_{\mathrm{e}}=2,388.15, p=$ .11 ; and $F 1(1,69)=3.09, M S_{\mathrm{e}}=663.15, p=.08, F 2<1$, respectively]. The 1436 and 6341 conditions did not significantly differ from the DDDD condition.

The ANOVA conducted on the arcsine transformations of percent errors to word stimuli showed no effect of prime type $\left[F(3,69)=1.89, M S_{\mathrm{e}}=0.78, p=.14\right]$. The ANOVA conducted on correct RTs to nonwords showed that RTs were not significantly affected by the different types of prime $(F<1)$.

When the prime stimulus contained the same letters as the target but in a partially scrambled order, no significant priming effects were obtained. The priming effect depended crucially on the relative position of the letters shared by primes and targets. Only when the two stimuli 


\section{EXPERIMENT 3B: WORDS}

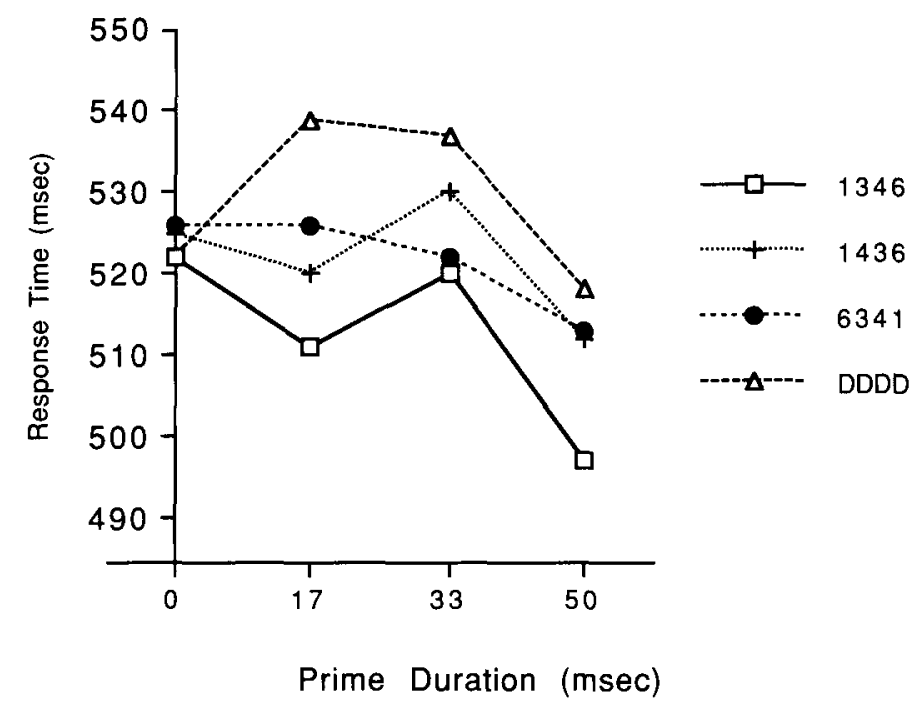

Figure 2. Variation in mean RT (in milliseconds) as a function of prime exposure duration and prime type in Experiment 3B. The numbers refer to letters occupying the specified position in the target; $D$ denotes a letter not present in the target.

had the same letters in the same relative position was significant facilitation observed. In Experiment 3B, we tested the same stimuli with the incremental priming procedure.

\section{Method of Experiment 3B}

Subjects. Four undergraduate students at the University of Provence participated as subjects in fulfillment of a course requirement. All were French speakers and had normal or correctedto-normal vision.

Stimuli and Design. The stimuli and design were the same as those in Experiment 3A.

Procedure. Each subject participated in four sessions on different days. In each session, the subjects received the four lists in the order of a counterbalanced Latin-square design with a different prime duration. The stimuli presentation conditions were the same as in Experiment 3A, but, like in Experiment 1, four prime durations were used. The prime was exposed for $0,17,33$, or $50 \mathrm{msec}$, giving the four levels of the factor prime duration. The order of prime duration was also counterbalanced according to a Latinsquare design, such that different subjects were tested with different prime durations on successive days.

\section{Results and Discussion of Experiment 3B}

ANOVAs both by subjects and by items were performed with the factor prime type and prime duration as within-subjects and within-items factors. Prime type significantly affected RTs $\left[F 1(3,9)=4.96, M S_{\mathrm{e}}=140.56\right.$, $\left.p=.02 ; F 2(3,177)=4.51, M S_{\mathrm{e}}=2,192.83, p<.01\right]$. The factor prime duration was significant only in the item analysis $\left[F 2(3,177)=7.80, M S_{\mathrm{e}}=1,591.84, p<.001\right.$; $F 1<1]$. No other source reached the significance level. In Figure 2, the evolution of mean RT across prime exposure duration is plotted for each priming condition.
A priori planned comparisons among the means showed a significant within-condition inhibition for the DDDD condition at 17 and $33 \mathrm{msec}$ of prime duration. When the prime was presented for 17 or $33 \mathrm{msec}$, RTs were longer than in the corresponding $0-\mathrm{msec}$ baseline condition [at $17 \mathrm{msec}, F 1(1,27)=4.72, M S_{\mathrm{e}}=107.80, p=.03$, $F 2(1,531)=4.54, M S_{e}=1,604.9, p=.03$; at $33 \mathrm{msec}$, $F 1(1,27)=4.2, M S_{\mathrm{e}}=107.8, p=.05, F 2(1,153)=2.91$, $\left.M S_{\mathrm{e}}=1,604.90, p=.08\right]$. For all the following planned comparisons based on the present ANOVA, the $M S_{\mathrm{e}} \mathrm{s}$ were 107.80 and $1,604.90$ for the subjects and items analyses, respectively. The within-condition facilitation for the 1346 condition at $50 \mathrm{msec}$ of prime duration was significant: RTs were faster than in the corresponding $0-\mathrm{msec}$ condition $[F 1(1,27)=11.04, p<.01 ; F 2(1,531)=10.69$, $p<.01]$. The 1436 condition and the 6341 condition showed no significant facilitatory or inhibitory effects (no significant differences between the 0 -msec condition and the other exposure durations).

Let us now examine the between-condition priming effects at each prime duration. At $0 \mathrm{msec}$, as required by the incremental priming technique, no differences were observed. At $17 \mathrm{msec}$, RTs in the DDDD condition were significantly slower than RTs in the 1346 condition and the 1436 condition $[F 1(1,27)=13.46, p<.01, F 2(1,531)=$ $11.06, p<.001$; and $F 1(1,27)=6.17, p=.02, F 2(1,531)=$ $6.69, p<.01$, respectively]. At $33 \mathrm{msec}$, again, RTs in the DDDD condition were slower than those in the 1346 condition $[F 1(1,27)=5.22, p=.03 ; F 2(1,531)=5.12$, $p=.02]$, thus confirming the result obtained in Experiment $3 \mathrm{~A}$. The difference between the DDDD condition 
Table 5

Mean RTs (in Milliseconds) and Percent Errors (PEs) Obtained to Nonword Targets in Experiment 3B as a Function of Prime Duration and Prime Type

\begin{tabular}{|c|c|c|c|c|c|c|c|c|}
\hline \multirow[b]{3}{*}{ Prime Type } & \multicolumn{8}{|c|}{ Prime Duration (msec) } \\
\hline & \multicolumn{2}{|c|}{0} & \multicolumn{2}{|c|}{17} & \multicolumn{2}{|c|}{33} & \multicolumn{2}{|c|}{50} \\
\hline & RT & PE & RT & $\mathrm{PE}$ & RT & PE & RT & PE \\
\hline 1346 & 552 & 4.58 & 570 & 4.58 & 555 & 5.83 & 543 & 4.17 \\
\hline 1436 & 552 & 6.15 & 565 & 3.33 & 567 & 5.83 & 547 & 5.0 \\
\hline 6341 & 558 & 7.5 & 567 & 6.66 & 563 & 5.83 & 539 & 3.75 \\
\hline DDDD & 557 & 4.17 & 580 & 6.66 & 565 & 6.25 & 549 & 7.5 \\
\hline
\end{tabular}

and the 4231 condition at this exposure duration was significant in the subjects analysis and only marginally so in the items analysis $[F 1(1,27)=4.25, p=.049 ; F 2(1,531)=$ $3.36, p=.07]$. At $50 \mathrm{msec}$ of prime duration, RTs in the 1346 condition were faster than RTs in the DDDD condition $[F 1(1,27)=8.22, p<.01 ; F 2(1,531)=7.99, p<.01]$, the 1436 condition $[F 1(1,27)=4.13, p=.05 ; F 2(1,531)=$ $4.18, p=.04]$, and the 6341 condition $[F 1(1,27)=4.59$, $p=.04 ; F 2(1,531)=4.65, p=.03$ ].

The arcsine-transformed percent errors to word data were submitted to an ANOVA in the same way as the RT data. The effect of type of prime was significant $[F(3,9)=$ $\left.4.06, M S_{\mathrm{e}}=0.007, p=.04\right]$. Fewer errors were made in the 1346 condition than in the other three priming conditions. No other source proved significant $(F \mathrm{~s}<1)$. The average error rates for the $1346,1436,6341$, and DDDD prime conditions, respectively, at each prime duration were as follows: at $0 \mathrm{msec}, 2.92,3.33,5.42$, and 5.42 ; at $17 \mathrm{msec}, 2.92,4.17,4.58$, and 6.25 ; at $33 \mathrm{msec}, 3.33,3.75$, 4.58, and 5.42; at $50 \mathrm{msec}, 3.75,4.17,4.17$, and 6.25 .

Nonword RTs and error rates are reported in Table 5. No significant effects were obtained in the ANOVA performed on correct RTs to nonwords with the factors prime type and prime duration as within-subjects factors (all $F$ s $<1$ ).

The present results showed that the priming effect obtained when the prime was exposed for either 17 or $33 \mathrm{msec}$ was due to the inhibition obtained in the DDDD condition, whereas the effect obtained when the prime was exposed for $50 \mathrm{msec}$ was due to the facilitation obtained in the 1346 condition. Since the number of different letters in the DDDD condition and the number of shared letters in the 1346 condition were equivalent, the faster rise in inhibition from mismatching letters, relative to the development of facilitation from shared letters, could not have been due to any differences at this level (as could have been the case in Experiment 1). This point will be examined in the General Discussion section.

The facilitation obtained from primes in which relative letter position in the target was maintained is an example of length-independent, relative-position priming. This suggests that, on presentation of the prime stimulus (a string of letters), words containing letters that are in the prime stimulus and that maintain their relative order in that stimulus receive the most activation. When primes contained letters from the target word but in a different order, no facilitation was observed.

\section{EXPERIMENT 4}

The aim of Experiment 4 was twofold: (1) to further investigate the issue of relative position versus absolute position coding in orthographic priming and (2) to examine the influence of visual complexity on the inhibitory priming effects of filler characters (items present in the prime stimulus that are not present in the target). In Experiments 2 and 3 , we obtained significant priming effects for fourletter primes composed of the four consonants of a sixletter target word in the same relative position (the 1346 condition). However, in Experiment 2, no effect was obtained with six-letter primes containing the four consonants in the same absolute position as the target and two unrelated letters. The lack of the priming effect was attributed to the interference generated by the two unrelated letters. In Experiment 4, we compare a relative-position priming condition with an absolute position priming condition not including any unrelated letter. More specifically, we used the same target words of Experiment 3 and now compared a four-letter prime condition (1346) with a prime containing the same four letters plus two additional keyboard signs ( - or $\%$ ) placed in the position of the vowels $(1-34-6$, or $1 \% 34 \% 6)$ and a prime containing only percent signs $(\% \% \% \% \% \%)$. This manipulation allowed us to test for effects of visual complexity on the interference generated by prime stimuli (the percent sign was visually more complex than the minus sign). Furthermore, the $1-34-6$ priming condition was expected to maximize absolute position priming effects since the appropriate position information was supplied while minimizing possible interference effects. The incremental priming technique was used.

\section{Method}

Subjects. Four graduate students at University of Provence volunteered to participate as subjects. All were native French speakers with normal or corrected-to-normal vision.

Stimuli and Design. The same 60 target words and 60 target nonwords of Experiment 3 were used. Four priming conditions were devised. In the first condition (the 1346 condition), the prime was the ordered sequence of the four consonants of the target (e.g., BLCN, BALCON), as in Experiment 3. In the second condition (the 


\section{EXPERIMENT 4: WORDS}

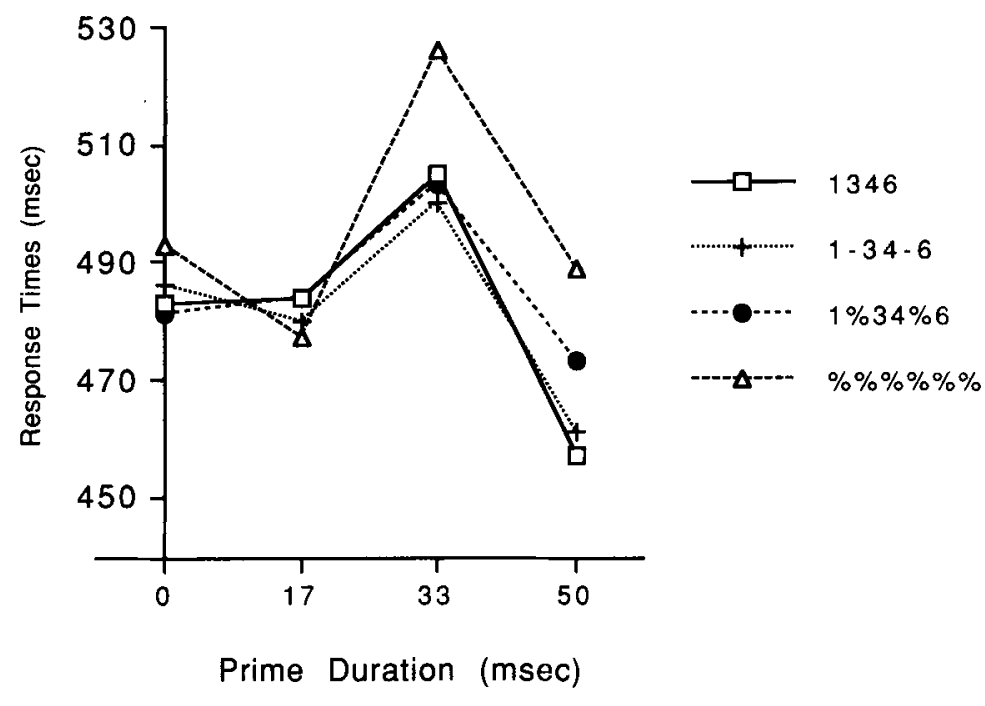

Figure 3. Variation in mean RT (in milliseconds) as a function of prime exposure duration and prime type in Experiment 4. The numbers refer to letters occupying the specified position in the target; the "\%" and "-" signs refer to the presence of such characters in the prime stimulus.

$1-34-6$ condition), the prime contained the four consonant and two minus signs replacing the vowels of the target word (e.g., B-LC-N, BALCON). In the third condition the ( $1 \% 34 \% 6$ condition), the prime contained the four consonants and two percentage signs replacing the vowels of the target word (e.g., $\mathrm{B} \% \mathrm{LC} \% \mathrm{~N}$, BALCON). In the fourth condition, the prime was formed by six percentage signs (or i.e., $\% \% \% \% \% \%$ ). Each target stimulus was presented in the four priming conditions, giving the four levels of the factor prime type (see Table 1). As in Experiments 1-3, four lists were constructed in which prime-target pairs were rotated according to a Latin-square design. Each list contained 120 targets ( 60 words and 60 nonwords), 15 words and nonwords for each priming condition. The four lists were presented four times, at different prime durations $(0,17,33$, or $50 \mathrm{msec})$, giving the four levels of the factor prime duration.

Procedure. Each subject participated in four experimental sessions. In each session, she/he received the four lists in the order of a counterbalanced Latin-square design with a different prime duration $(0,17,33$, or $50 \mathrm{msec})$. The order of prime duration was also counterbalanced between subjects, so that different subjects were tested with different priming durations on different days. Target and prime stimuli had the same size as those in Experiments 1-3: the target (six letters) was $2 \mathrm{~cm}$ long, the four-letter prime was $0.9 \mathrm{~cm}$ long, and the six-letter prime was $1.4 \mathrm{~cm}$ long. At a viewing distance of $60 \mathrm{~cm}$, they subtended $3.82^{\circ}, 1.71^{\circ}$, and $2.67^{\circ}$ of visual angle, respectively. For all other details, the procedure was the same as in Experiments 1-3.

\section{Results and Discussion}

Mean correct RTs to word targets in each priming condition are plotted in Figure 3 as a function of prime duration.

ANOVAs by subjects and by items were performed on correct RTs to words. There was a main effect of prime type $\left[F 1(3,9)=6.26, M S_{\mathrm{e}}=119.45, p=.013 ; F 2(3,177)=\right.$ $\left.7.86, M S_{\mathrm{e}}=1,668.6, p=.0001\right]$. The effect of prime duration was significant only in the analysis by items $\left[F 2(3,177)=41.88, M S_{\mathrm{e}}=1,576.87, p<.0001 ; F 1(3,9)=\right.$ $\left.0.57, M S_{\mathrm{e}}=7,313.24, p=.65\right]$, as was the prime type $\times$ prime duration interaction $\left[F 2(9,531)=2.68, M S_{\mathrm{e}}=\right.$ $\left.1,696.2, p<.01 ; F 1(9,27)=1.73, M S_{\mathrm{e}}=152.83, p=.13\right]$.

Comparisons among the means showed significant within-condition inhibition (RTs longer than those in the 0 -msec prime duration) for all prime conditions at $33 \mathrm{msec}$ of prime duration [for the $\% \% \% \% \% \%$ condition, $F 1(1,27)=14.49, p<.001, F 2(1,531)=23.94, M S_{\mathrm{e}}=$ $1,696.2, p<.0001$; for the $1 \% 34 \% 6$ condition, $F 1(1,27)=$ $6.38, p=.018, F 2(1,531)=9.43, p<.01$; for the $1-34-6$ condition, $F 1(1,27)=2.47, p=.12, F 2(1,531)=2.83, p=$ .09 ; for the 1346 condition, $F 1(1,27)=6.44, p=.017$, $F 2(1,531)=39.96, p<.0001]$. For these and the following comparisons based on the present ANOVA, the $M S_{\mathrm{e}} \mathrm{s}$ were 152.83 and $1,696.21$ for the subjects and items analyses, respectively. The within-condition facilitation for both the 1346 condition and the $1-34-6$ condition at $50 \mathrm{msec}$ of prime duration was also significant. In these conditions, RTs were faster than in the corresponding 0 -msec baseline conditions $[F 1(1,27)=8.56, p<.01, F 2(1,531)=10.12$, $p<.01 ;$ and $F 1(1,27)=8.31, p<.01, F 2(1,531)=11.83$, $p<.001$, respectively].

As concerns across-condition priming effects, no differences were obtained at 0 and $17 \mathrm{msec}$ of prime duration. At $33 \mathrm{msec}$, RTs in the $\% \% \% \% \% \%$ condition were slower than in the other three priming conditions [the $1 \% 34 \% 6$ condition, $F 1(1,27)=7.02, p=.01, F 2(1,532)=$ $12.2, p<.001$; the $1-34-6$ condition, $F 1(1,27)=9.07$, $p<.01, F 2(1,531)=17.93, p<.0001$; the 1346 condition, 
Table 6

Mean RTs (in Milliseconds) and Percent Errors (PEs) Obtained to Nonword Targets in Experiment 4 as a Function of Prime Duration and Prime Type

\begin{tabular}{|c|c|c|c|c|c|c|c|c|}
\hline \multirow[b]{3}{*}{ Prime Type } & \multicolumn{8}{|c|}{ Prime Duration (msec) } \\
\hline & \multicolumn{2}{|c|}{0} & \multicolumn{2}{|c|}{17} & \multicolumn{2}{|c|}{33} & \multicolumn{2}{|c|}{50} \\
\hline & RT & $\mathrm{PE}$ & RT & $\mathrm{PE}$ & RT & PE & RT & $\mathrm{PE}$ \\
\hline$\overline{1346}$ & 503 & 3.75 & 491 & 2.92 & 517 & $4 . \overline{17}$ & 473 & 3.33 \\
\hline $1-34-6$ & 503 & 4.58 & 489 & 3.33 & 520 & 5.42 & 479 & 5.00 \\
\hline $1 \% 34 \% 6$ & 497 & 5.00 & 494 & 4.58 & 520 & 5.83 & 486 & 5.83 \\
\hline$\% \% \% \% \% \%$ & 508 & 4.17 & 496 & 3.33 & 545 & 4.58 & 508 & 4.58 \\
\hline
\end{tabular}

$F 1(1,27)=5.95, p=.02, F 2(1,531)=10.97, p=.001]$. At 50 -msec prime exposures, RTs in the $\% \% \% \% \% \%$ condition were slower than in all the other priming conditions [the 1346 condition, $F 1(1,27)=29.85, p<.0001$, $F 2(1,531)=10.12, p<.01$; the $1-34-6$ condition, $F 1(1,27)=8.31, p<.01, F 2(1,531)=11.83, p<.001$; the $1 \% 34 \% 6$ condition, $F 1(1,27)=3.38, p=.076, F 2(1,531)=$ $4.59, p=.033]$. At the 50-msec exposure duration, the differences between both the 1346 condition versus the $1 \% 34 \% 6$ condition and the $1-34-6$ versus the $1 \% 34 \% 6$ condition were marginally significant $[F 1(1,27)=3.16$, $p=.087, F 2(1,531)=3.57, p=.059$; and $F 1(1,27)=$ $1,79, p=.191, F 2(1,531)=3.03, p=.082$, respectively]. There was no significant difference between the 1346 condition and the 1-34-6 condition.

The arcsine-transformed percent errors to word targets were submitted to an ANOVA by subjects in the same way as the RT data. No significant effects were obtained (all $F_{\text {S }}>1$ ). The average error rates for the $1346,1-34-6$, $1 \% 34 \% 6$, and $\% \% \% \% \% \%$ prime conditions, respectively, at each prime exposure were as follows: $0 \mathrm{msec}$, $2.92,4.17,2.50$, and $1.25 ; 17 \mathrm{msec}, 2.08,3.75,5.00$, and $2.92 ; 33 \mathrm{msec}, 4.58,2.58,3.33$, and $5.42 ; 50 \mathrm{msec}, 3.33$, $2.08,2.50$, and 4.58 .

Nonword data are reported in Table 6. Mean RTs to nonwords were submitted to an ANOVA by subjects with the same factors as the words (i.e., prime type and prime duration). Since, contrary to the results of Experiments 1 and 2, some of the effects were significant, an ANOVA by items was also performed. One of the items was excluded from these analyses since 3 subjects consistently considered it a word (by error, the infinitive form of a verb, VANTER, was included in the nonword stimuli).

There was a main effect of prime type $[F 1(3,9)=27.57$, $M S_{\mathrm{e}}=40.84, p=.0001 ; F 2(3,174)=5.88, M S_{\mathrm{e}}=3,797.09$, $p<.001]$. Mean RTs in the $\% \% \% \% \% \%$ condition $(514 \mathrm{msec})$ were slower than in the other three priming conditions $(496,498$, and $499 \mathrm{msec}$ for the $1346,1-$ $34-6$, and $1 \% 34 \% 6$ conditions, respectively). The factor prime duration was significant in the analysis by items but not in the analysis by subjects $\left[F 2(3,174)=37.95, M S_{\mathrm{e}}=\right.$ $1,946.60, p<.0001 ; F 1(3,9)=0.40, M S_{\mathrm{e}}=11,910.61$, $p=.75]$. The interaction between the two factors was significant in the analysis by items and marginally so in the analysis by subjects $\left[F 2(9,522)=2.61, M S_{\mathrm{e}}=1,706.08\right.$, $\left.p=.023 ; F 1(9,27)=2.00, M S_{\mathrm{e}}=105.56, p=.079\right]$.

Planned comparisons among the means showed that the following differences were significant by subject and by item (for these and the following comparisons based on the present ANOVA, the $M S_{\mathrm{e}} \mathrm{s}$ were 105.56 and $1,706.08$ for the subject and the item analyses, respectively). There was a significant within-condition inhibition at $33 \mathrm{msec}$ of prime duration for the $\% \% \% \% \% \%$ condition $[F 1(1,27)=26.43, p<.0001 ; F 2(1,522)=27.65$, $p<.0001]$, for the $1 \% 34 \% 6$ condition $[F 1(1,27)=9.62$, $p<.01 ; F 2(1,531)=8.34, p<.01]$, for the $1-34-6$ condition $[F 1(1,27)=5.57, p=.03 ; F 2(1,531)=8.60, p<$ $.01]$, and for the 1346 condition $[F 1(1,27)=3.66, p=.066$; $F 2(1,531)=2.59, p=.11]$. Both the 1346 condition and the 1-34-6 condition showed significant facilitation at $50 \mathrm{msec}$ of prime duration $[F 1(1,27)=17.71, p<.001$, $F 2(1,522)=18.37, p<.0001$; and $F 1(1,27)=11.47$, $p<.01, F 2(1,522)=7.79, p<.01$, respectively]. For the between-condition priming effects, at 33 and $50 \mathrm{msec}$ of prime duration, RTs in the $\% \% \% \% \% \%$ condition were longer than in the other three priming conditions [at $33 \mathrm{msec}$, in the 1346 condition, $F 1(1,27)=15.10, p<$ $.001, F 2(1,531)=18.27, p<.0001$; at $33 \mathrm{msec}$, in the $1-$ $34-6$ condition, $F 1(1,27)=11.99, p<.01, F 2(1,531)=$ $12.43, p<.001$; at $33 \mathrm{msec}$, in the $1 \% 34 \% 6$ condition, $F 1(1,27)=12.37, p<.01, F 2(1,531)=17.57, p<.001$; at $50 \mathrm{msec}$, in the 1346 condition, $F 1(1,27)=23.37, p<$ $.0001, F 2(1,531)=25.43, p<.0001$; at $50 \mathrm{msec}$, in the $1-$ $34-6$ condition, $F 1(1,27)=16.18, p<.001, F 2(1,531)=$ $16.99, p<.0001$; at $50 \mathrm{msec}$, in the $1 \% 34 \% 6 \%$ condition, $F 1(1,27)=9.15, p<.01, F 2(1,531)=11.01, p=.001]$.

The arcsine-transformed percent errors to nonwords were submitted to a by-subjects ANOVA with prime type and prime duration as main factors. No significant effects were obtained.

The results of Experiment 4 show an almost identical pattern of effects for the 1-34-6 "absolute position" primes and the 1346 "relative position" primes. There was no indication whatsoever of a superiority for absolute position primes. This suggests that information concerning absolute position (i.e., length dependent position-in-string information) adds nothing over and above the information provided by relative-position primes. This result corroborates the hypothesis of a relative-position coding mechanism in visual word recognition.

The longer RTs obtained in the $1 \% 34 \% 6$ condition, relative to the $1-34-6$ condition, at 50 -msec prime exposures shows that the interference generated by a prime stimulus was influenced by the visual complexity of filler characters in the prime. The percent sign was visually more complex than the minus sign and resulted in stronger interference in target processing. We discuss some of the possible mechanisms in the General Discussion section.

Finally, contrary to what was found in Experiments 1-3, significant priming effects were obtained with nonword targets in Experiment 4. In this experiment, we used a 
series of percentage symbols as the within-condition baseline. The larger across-condition priming effects could therefore have been due to greater interference from this type of prime relative to the different letters primes used in the other experiments. However, although the withincondition analysis did indeed show greater interference from the neutral primes in Experiment 4, it also revealed greater facilitation for primes sharing letters with targets. Thus, decision times to say that a letter string is not a word can be facilitated when primes share letters with the target nonword. The fact that this result was obtained only in one of the four experiments reported here invites caution in any attempt at an interpretation. Ideally, this result should be discussed within the framework of a model of how nonword decisions are made in the lexical decision task (e.g., Grainger \& Jacobs, 1996) and how subjects may modify response criteria as a function of experimental context. Unfortunately, this is beyond the scope of the present study.

\section{GENERAL DISCUSSION}

The present experiments show that orthographic priming effects obtained using the masked prime paradigm and the lexical decision task vary as a function of (1) the number of letters shared by prime and target, (2) whether or not the shared letters occupied the same relative position in prime and target, and (3) the items used (different letters or nonalphabetic symbols) to provide position information for the shared letters.

The starting point for this work was a series of experiments in which we failed to obtain significant priming when prime stimuli contained two letters of the target word plus two unrelated letters (e.g., JKZR-JOUR). Pilot work demonstrated that this absence of priming was independent of prime-target size compatibility or case compatibility. Two possible reasons for the absence of priming effects were entertained. One possibility is that the facilitatory effects of letters shared by prime and target are cancelled by the inhibitory effects of different letters. The other possibility is that a minimum amount of orthographic overlap between prime and target (greater than $50 \%$ ) is required in order to observe facilitatory orthographic priming. We will examine each of these possibilities in turn.

Concerning the inhibitory effects of letters in the prime stimulus that are not present in the target word, Experiment 1 demonstrated that using a plus sign $(+)$ to replace different letters resulted in significant priming effects from two shared letters. Experiment 4 further demonstrated that degree of visual complexity of filler characters (comparing the minus sign with the percentage symbol) influenced priming effects. Significantly stronger effects were obtained with the less complex filler character (the minus sign). A further aspect of the effects of character complexity was observed in the within-condition priming effects obtained in Experiments 1, 3B, and 4. Primes composed of percentage signs (Experiment 4 ) generated more within-condition inhibition on word and nonword targets, relative to the effects of different letter primes tested in Experiments 1 and $3 \mathrm{~B}$.

The second possible reason for our failure to obtain significant priming effects in extensive pilot work concerns a hypothesized minimum degree of orthographic overlap between prime and target necessary to obtain observable priming effects. In Experiment 2, we increased the degree of orthographic overlap from two out of four letters to four out of six $(66.6 \%)$. This increase in orthographic overlap was not sufficient in itself to produce significant effects of orthographic priming. Priming was obtained only when no unrelated letters were present in the prime stimulus (e.g., BLCN-BALCON). The presence of two unrelated letters in one of the priming conditions tested in Experiment 2 (e.g., BSLCRN-BALCON) resulted in nonsignificant priming.

In line with this latter result, it should be noted that many prior studies, using the masked prime paradigm and the lexical decision task, have reported null effects when manipulating even higher levels of orthographic overlap (typically $75 \%$ or above) than in the present experiments. Several studies using 50 - to $60-\mathrm{msec}$ prime exposures have failed to observe across-condition priming effects when primes share all but one letter with targets, the different letter forming a nonword (e.g., parn-PART compared with nold-PART; see, e.g., Ferrand \& Grainger, 1992, 1994; Forster et al., 1987). Ferrand and Grainger (1992) argued that the nonword neighbor primes used in these studies generate inhibition via the activation of competing word units, such as the word PARK in the example given above. Thus, increasing the degree of prime-target orthographic overlap does not necessarily give rise to facilitatory priming, since this increases the likelihood that competitive processes will influence priming. However, when primes are not orthographic neighbors of targets (as in the present experiments), post hoc analyses of our data showed that there is minimal influence of the number of possible words that can be formed from the prime letters. In what follows, we show how the IA model (McClelland \& Rumelhart, 1981) provides a coherent account of these variations in effects of orthographic priming as a function of the degree of orthographic overlap and filler character complexity.

\section{The IA Model and Orthographic Priming}

The IA model implements the basic principles of a whole class of localist connectionist models of human cognition (Grainger \& Jacobs, 1998). Compatibility between representations at different levels generates mutual excitation, whereas incompatibility engenders inhibition. Furthermore, units within the same level mutually inhibit each other. Grainger and Jacobs (in press) have recently discussed how the combination of these different principles can account for a large range of orthographic priming phenomena. In the following analysis, we examine the extent to which the model can account for effects of num- 


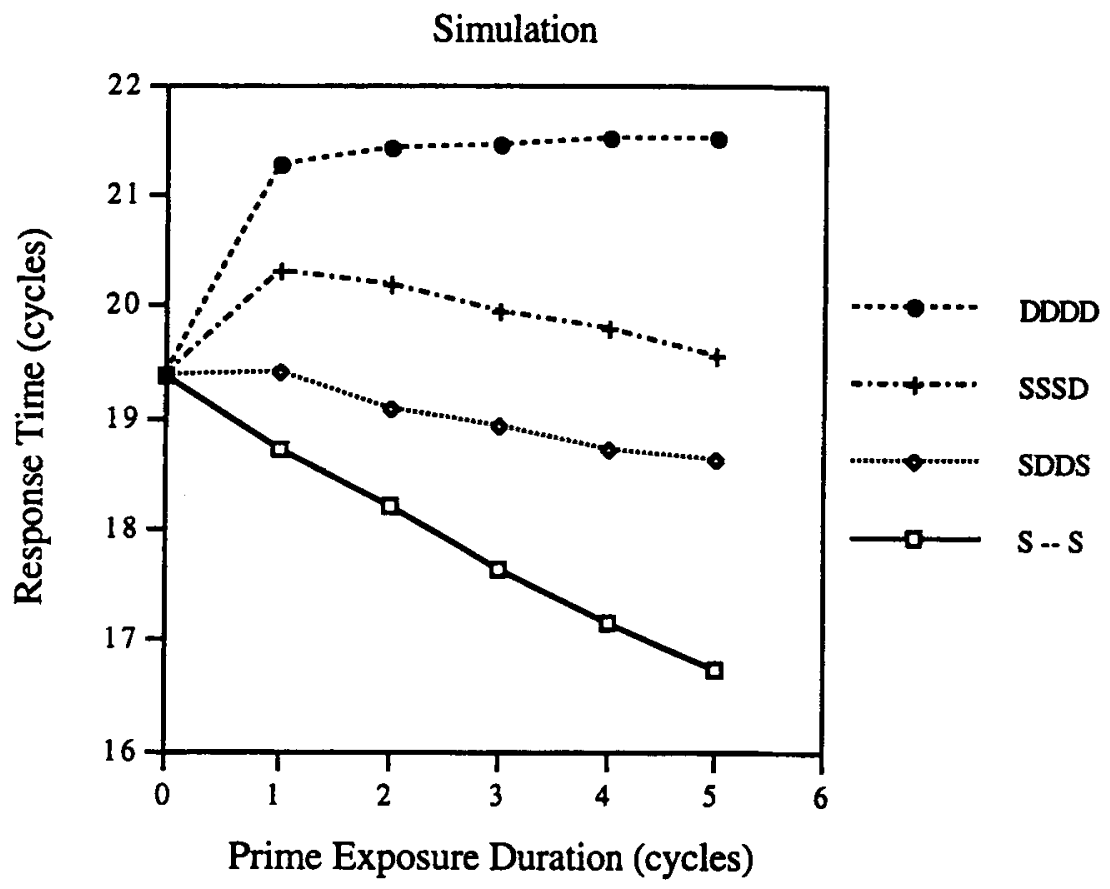

Figure 4. Mean number of cycles for word units in the IA model to reach a fixed activation criterion of .68 in the four priming conditions and six prime exposure durations tested. $S$ denotes same letter as in target; $D$ denotes a different letter from the target. In the $S--S$ prime condition, no feature units were activated at positions 2 and 3 .

ber of letters shared by prime and target and type of filler character. This analysis is supported by a simulation run on the IA model, the results of which are presented in Figure 4.

Returning to the example given above (parn-PARK), within the framework of the IA model, the letters $\mathrm{P}, \mathrm{A}$, and $\mathrm{R}$, of the nonword prime PARN, cause a rise in activation in word units that contain these three letters in the appropriate position (e.g., PARK, PART). When the target word PART is presented, the competing word PARK continues to receive significant activation from the letters $P$, $A$, and $R$ in PART. Lateral inhibition between simultaneously activated word units slows the rate of rise in activation of the target word. This account of null orthographic priming effects from nonword neighbor primes (i.e., primes that differ from targets by a single letter) makes two clear predictions that have been confirmed: (1) Inhibitory effects of orthographic priming occur when the primes are high-frequency word neighbors of targets (Drews \& Zwitserlood, 1995; Segui \& Grainger, 1990), and (2) facilitatory effects of orthographic priming will be stronger when primes are not orthographic neighbors of targets (the present experiments). Jacobs and Grainger (1992) have already presented simulation work illustrating the first prediction. The simulation study to be presented below illustrates the second prediction.

We ran a simulation with the IA model using the target words and the SDDS and DDDD primes of Experiment 1. We tested two additional prime conditions in this simula- tion: $S--S$ and SSSD. In the $S--S$ simulation, no feature units were activated at positions 2 and 3 . This therefore represents a simulation of minimal filler character complexity, as tested in Experiment 4. In the SSSD simulation, a new series of nonword primes were prepared. These shared all but one letter with the target words, and the different letter could be at any of the four possible positions in the word. The latter type of prime corresponds to what is typically tested in the nonword neighbor priming studies mentioned above.

The results of this simulation study are shown in Figure 4. The simulations used the four-letter French lexicon and the word unit response read-out criterion implemented by Grainger and Jacobs (1996). All the original parameter settings of the IA model remained unchanged. The experimental stimuli (a total of $4 \times 80$ prime-target pairs) were tested at six different prime exposures in a deterministic simulation. Figure 4 shows number of cycles to reach a fixed activation criterion of 0.68 averaged across the different prime-target pairs for a given priming condition and prime exposure duration $(0,1,2,3,4$, or 5 cycles).

The within-condition priming effects produced by the simulation show clear inhibition from all letter different primes (DDDD), as was observed in Experiments 1 and 3B. They also show clear within-condition facilitation when primes share two letters with targets, and filler characters are minimally complex $(\mathrm{S}--\mathrm{S})$. This result was also observed in Experiment 1 . The faster rise in inhibitory effects relative to facilitatory effects in the simulation was 
also observed in Experiments 1 and 3B. In the model, this is due to the greater strength of inhibitory connections between features and letters $(0.15)$ relative to the strength of excitatory feature-to-letter connections $(0.005)$. Note that these values are not arbitrary parameter settings but are values that were selected after extensive simulation work as those that provided the best fit with the target data set in the original studies (McClelland \& Rumelhart, 1981; Rumelhart \& McClelland, 1982). It should be further underlined that no parameter adjustments were made in an attempt to bring the simulation results in line with the present experimental results.

In between the upper and lower curves lie the results of the SDDS and SSSD conditions. These generate relatively small within-condition priming effects, with the SSSD being slightly inhibitory and the SDDS curve slightly facilitatory. As discussed above, the fact that the model predicts slower RTs following SSSD (neighbor) primes than following SDDS primes is due to the inhibition generated by orthographic neighbors of the prime stimulus that are also orthographic neighbors of the target. Indeed, if we distinguish between SSSD primes that share a neighbor with the target word (e.g., parn-PARK: PART) and those that do not (e.g., luch-LUCK), then the SSSD curve moves above the DDDD in the first case and below the SDDS curve in the second case.

The difference between the $\mathrm{S}--\mathrm{S}$ and SDDS curves in Figure 4 simulates the effects of filler character complexity observed in the present study (S++S vs. SDDS in Experiment 1 , and $\mathrm{S}--\mathrm{S}$ vs. $\mathrm{S} \% \% \mathrm{~S}$ in Experiment 4$)$. The model captures these effects by variations in the degree of feature-letter inhibition that is generated by these different stimuli. The greater the number of features in the filler character that are not present in the corresponding target letter, the greater the inhibition directed toward the target letter representation. These simulated effects of filler character complexity are not the result of letterletter inhibition in the SDDS condition, since replacing the different letters with more complex nonletter characters produced a pattern almost identical to the SDDS curve.

The model fares less well with respect to acrosscondition priming effects. The simulation generates quite large differences between the SDDS condition and the DDDD condition, whereas we systematically failed to obtain significant differences in our experiments. However, this across-condition effect in the simulation appears to be mainly due to high levels of within-condition inhibition in the unrelated prime condition. It appears that the model exaggerates the inhibitory influence of such primes, particularly at the longest prime exposure durations. Clearly, future explorations of the model (beyond the scope of the present study; but see Grainger \& Jacobs, 1996, and Jacobs, Rey, Ziegler, \& Grainger, 1998, as example developments of the IA model) could attempt to uncover what critical modifications are necessary to bring the simulations more in line with the experimental results. One area for future work concerns the simplifying assumption of position-specific letter coding of the original IA model, maintained in the present simulations. Here, we will examine the limitations of such a coding scheme and suggest alternatives to be implemented in future versions of the model.

\section{Relative-Position Priming Effects}

The present experiments were designed to test for effects of relative letter position versus absolute letter position in orthographic priming. Given a six-letter string BALCON, a stimulus BSLCRN is said to preserve the absolute position of letters $B, L, C$, and N, whereas the stimulus BLCN is said to preserve the relative position of these letters (e.g., $L$ is to the right of $B$ and to the left of $C$ in both stimuli). The stimuli NLCB and BCLN preserve letter identity but violate the relative position of certain letters. Testing the effects of these different types of prime can therefore inform us about how the visual word recognition system codes information concerning the position of letter identities in the stimulus string.

The results of the present experiments clearly favor a relative-position coding account of letter-in-string processing. We systematically failed to observe any adverse effects of changing the absolute position of letters shared between prime and target while maintaining their correct relative position (e.g., BLCN-BALCON). Inserting filler letters or characters (e.g., BSLCRN, B-LC-N) to provide absolute position information never led to significantly larger priming effects. Furthermore, the results of Experiment 3 clearly demonstrate that when the relative position of two out of four letters is violated, then RTs do not differ significantly from the unrelated prime condition (no across-condition priming) nor from the zero prime duration baseline (no within-condition priming). On the other hand, if all four prime letters maintain their relative position in the target string, but not their absolute position in the target, significant across-condition and withincondition priming arises.

These results therefore add support to the work of Humphreys et al. (1990) showing that some form of relative-position coding operates on printed strings of letters. In recent modeling work extending the original IA model (Jacobs et al., 1998), one such relative-position coding scheme has been adopted. The external letters (beginning and end letter) are taken as anchor points for this relative-position coding scheme, and all internal letters are coded relative to these points. Thus, the string BLACK will be coded as Int $=\mathrm{B}$, Int $+1=\mathrm{L}$, Int $+2=$ Fin $-2=A$, Fin $-1=C$, Fin $=K$, where Int stands for initial letter, and Fin stands for final letter in the string. The major motivation for adopting this particular coding scheme was to implement a single scheme and a single lexicon for words of varying length. The original IA model used a length-dependent absolute position coding scheme.

However, the scheme adopted by Jacobs et al. (1998) cannot account for the pattern of priming effects observed in Experiment 3 using four-letter primes and six-letter targets. In particular, it predicts equivalent priming for 1346 and 1436 primes, which both should be better than 
6341 primes. This is because external letters, but not internal letters, will be given the same relative-position coding in prime and target. This particular result motivates the following modified position coding scheme.

According to this new scheme, three anchor points are used in relative-position coding: the two external letters (as before) and the position of eye fixation (generally near the middle of the word). The latter anchor point simply serves to assign a minimal amount of relative-position information to internal letters. Knowing that a given letter is being fixated, while another is to the left and another to the right of fixation, provides an accurate ordering of these three letters. This coding scheme profits from the fact that the visual system has relatively precise information about the fixated letter and the two external letters and quite poor information about the remaining letters. The spaces adjacent to external letters not only diminish lateral inhibition on these letters but also provide very precise positional information. The letter at fixation benefits from the much higher density of cones in the center of the fovea, and the retinotopic mapping of information left and right of fixation can be used to infer the position of letters relative to this point.

Implementing such a letter position coding scheme in the IA model will allow us to provide precise quantitative tests of this proposal against relative-position priming effects obtained in human experimentation. The implementation, however, is not as straightforward as the above discussion might suggest. It raises the interesting and difficult question of how fixation position might be coded in the orthographic descriptions of words in memory. Empirical work on the optimal viewing position phe-

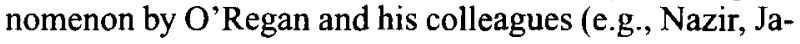
cobs, \& O'Regan, 1998; O'Regan \& Jacobs, 1992) and the preferred viewing position phenomenon (e.g., Rayner, 1979) should help provide the answer to this and related questions.

\section{Conclusions}

In the present study, we examined a certain number of necessary conditions for obtaining orthographic priming effects in the masked priming paradigm and the lexical decision task. We described the complex role played by the number of letters shared by primes and targets, as well as the role played by filler characters in the prime that are not present in the target word. Having done so, we were able to conclude in favor of a relative-position coding interpretation of the present results. Nowhere did we observe any sign of an advantage for supplying, in the prime stimulus, absolute position information about letters in the target stimulus. This result suggested a new letter position coding scheme that could be implemented in future developments of models of visual word perception. This proposal awaits testing with further experimental work of the kind described in the present work. We believe that the combination of masked priming methodology, and in particular the incremental priming technique (Jacobs et al., 1995), and localist connectionist modeling (Grainger \& Jacobs, in press) should help provide a clear answer to the question of how position information is combined with identity information about individual letters during the perception of printed words.

\section{REFERENCES}

BESNER, D., \& MCCANN, R. S. (1987). Word frequency and pattern distortion in visual word identification and production: An examination of four classes of models. In M. Coltheart (Ed.), Attention and performance XII: The psychology or reading (pp. 201-219). Hillsdale, NJ: Eribaum.

DAvIS, C., \& Forster, K. I. (1994). Masked orthographic priming: The effect of prime-target legibility. Quarterly Journal of Experimental Psychology, 47A, 673-697.

Drews, E., \& ZWITSERLOod, P. (1995). Morphological and orthographic similarity in visual word recognition. Journal of Experimental Psychology: Human Perception \& Performance, 21, 1098-1116.

EgETH, H. E., \& SANTEE, J. L. (1981). Conceptual and perceptual components of interletter inhibition. Journal of Experimental Psychology: Human Perception \& Performance, 7, 506-517.

EvETT, L. J., \& HuMPHREYS, G. W. (1981). The use of abstract graphemic information in lexical access. Quarterly Journal of Experimental Psychology, 33A, 325-350.

Ferrand, L., \& Grainger, J. (1992). Phonology and orthography in visual word recognition: Evidence from masked nonword priming. Quarterly Journal of Experimental Psychology, 45A, 353-372.

FERRAND, L., \& GRAINGER, J. (1994). Effects of orthography are independent of phonology in masked form priming. Quarterly Journal of Experimental Psychology, 47A, 365-382.

FORSTER, K. I. (1993). Form-priming and temporal integration in word recognition. In G. T. M. Altmann \& R. C. Shillcock (Eds.), Cognitive models of speech processing. The Sperlonga Meeting, II. (pp. 467-495). Howe, U.K.: Erlbaum.

ForSTER, K. I., \& Davis, C. (1984). Repetition priming and frequency attenuation in lexical access. Journal of Experimental Psychology: Learning, Memory, \& Cognition, 10, 680-698.

Forster, K. I., DAvis, C., SCHOKNeChT, C., \& CARTER, R. (1987). Masked priming with graphemically related forms: Repetition or partial activation? Quarterly Journal of Experimental Psychology, 39A, 211-251.

Grainger, J., \& JACOBS, A. M. (1996). Orthographic processing in visual word recognition: A multiple read-out model. Psychological Review, 103, 518-565.

Grainger, J., \& JACOBS, A. M. (1998). On localist connectionism and psychological science. In J. Grainger \& A. M. Jacobs (Eds.), Localist connectionist approaches to human cognition (pp. 1-38). Mawah, NJ: Erlbaum.

Grainger, J., \& Jacobs, A. M. (in press). Temporal integration of information in orthographic priming. Visual Cognition.

Humphreys, G. W., EvetT, L. J., \& Quinlan, P. T. (1990). Orthographic processing in visual word identification. Cognitive Psychology, 22, $517-560$.

Im8s, P. (1971). Etudes statistiques sur le vocabulaire français: Dictionnaire des fréquences. Vocabulaire littéraire des XIXe et XXe siècles. Paris: Librairie Marcel Didier.

JACOBS, A. M., \& GRAINGER, J. (1992). Testing a semistochastic variant of the interactive activation model in different word recognition experiments. Journal of Experimental Psychology: Human Perception \& Performance, 18, 1174-1188.

Jacobs, A. M., Grainger, J., \& Ferrand, L. (1995). The incremental priming technique: A method for determining within-condition priming effects. Perception \& Psychophysics, 57, 1101-1110.

JACOBS, A. M., ReY, A., Ziegler, J. C., \& Grainger, J. (1998). MROM-p: An interactive activation, multiple read-out model of orthographic and phonological processes in visual word recognition. In 
J. Grainger \& A. M. Jacobs (Eds.), Localist connectionist approaches to human cognition (pp. 147-188). Mahwah, NJ: Erlbaum.

MCClelland, J. L., \& Rumelhart, D. E. (1981). An interactive activation model of context effects in letter perception: Part 1 . An account of basic findings. Psychological Review, 88, 375-407.

NaZIR, T. A., Jacobs, A. M., \& O'RegAN, J. K. (1998). Letter legibility and visual word recognition. Memory \& Cognition, 26, 810-821.

O'ReGAN, J. K., \& JaCOBS, A. M. (1992). Optimal viewing position effects in word recognition: A challenge to current theory. Journal of Experimental Psychology: Human Perception \& Performance, 18, 185-197.

PaAp, K. R., Newsome, S. L., McDonald, J. E., \& SchvaneveldT, R. W. (1982). An activation-verification model for letter and word recognition: The word superiority effect. Psychological Review, 89, 573-594.

Peressotti, F., \& Grainger, J. (1995). Letter-position coding in random consonant arrays. Perception \& Psychophysics, 57, 875-890.
Peressotti, F., Job, R., Rumiati, R., \& Nicoletti, R. (1995). Levels of representation in visual word recognition. Visual Cognition, 2 , 421-450.

RAYNER, K. (1979). Eye guidance in reading: Fixation locations within words. Perception, 8, 21-30.

Rumelhart, D. E., \& MCClelland, J. L. (1982). An interactive activation model of context effect in letter perception: II. The contextual enhancement effect and some tests and extensions of the model. Psychological Review, 89, 60-94.

Segui, J., \& Grainger, J. (1990). Priming word recognition with orthographic neighbors: Effects of relative prime-target frequency. Journal of Experimental Psychology: Human Perception \& Performance, 16, 65-76.

(Manuscript received May 21, 1997; revision accepted for publication March 23, 1998.) 